\title{
Fault Diagnosis of a High-Speed Cam-Driven Pin Assembly System
}

\author{
Chi-Cheng Cheng, Yih-Tun Tseng, Cheng-Da Wu, and Der-Lin Wang \\ Department of Mechanical and Electromechanical Engineering, National Sun Yat-Sen University, Kaohsiung 80424, Taiwan \\ Correspondence should be addressed to Chi-Cheng Cheng; chengcc@mail.nsysu.edu.tw
}

Received 17 November 2015; Accepted 1 February 2016

Academic Editor: Wei Zhou

Copyright (c) 2016 Chi-Cheng Cheng et al. This is an open access article distributed under the Creative Commons Attribution License, which permits unrestricted use, distribution, and reproduction in any medium, provided the original work is properly cited.

\begin{abstract}
A cam-driven mechanical system applied for pin assembly of connectors of electrical devices is studied in this paper. Three cooperative cams are involved in the tasks of approaching, cutting, insertion, and restoring. In order to meet the demanded productivity growth, the operation speed tends to be elevated. However, high running speeds usually cause deficiencies of pin dropping and inaccurate positioning. Diagnosis is therefore conducted to explore their physical reasons so that modification of future mechanical design can be made. Frequency responses of experimental measurements show greater natural frequency and system stiffness caused by nonlinear dynamics for higher operation speed. It also appears that the clamping force is reduced and drift of the locked pin's location is induced for higher running speed. In addition, separation of the fixture system induced by contact oscillation generates clearance larger than the thickness of the pin. Based on the mathematical models obtained from the technique of system identification, deeper insight of the mechanical system and future system improvement can be highly expected.
\end{abstract}

\section{Introduction}

The cam is a mechanical transmission device that can easily convert its rotational motion to linear movement at the follower by direct contact. Many motion specifications at the follower including constant speed, varying speed, discontinuous motion, and swing movement can be achieved by different cam profile curves. Although some drawbacks such as being easy to wear and easy to generate noises exist, the cam is still widely applied to lots of mechanical systems in our daily life, for example, internal combustion engines, printing machines, machining centers, and mills, due to less space demand, straightforward mechanical structure, and simpler design process.

The cam has entered into the human's life for more than one hundred years. Researches on the cam system can be divided into two major categories, the kinematic characteristics analysis and the dynamic characteristics analysis [1]. The kinematic characteristics analysis focuses on geometry of the cam profile. Design of the cam profile usually requires smooth acceleration variation to avoid jump and bounce of mechanical components. Basically, less maximum acceleration reduces inertia force and smaller maximum velocity brings about smooth and quiet running operation. All design criteria become even more important for higher operation speed. How to judge all possible requirements to obtain a better cam profile keeps attracting attentions of researchers [2].

Chew et al. [3] proposed an optimization approach to tune parameters of the cam system, such as acceleration, contact stress, spring force, and pressure angle, for highspeed dwell-rise-dwell type cam systems. Young and Shoup [4] then tried to reduce vibration of mechanical components from a point of view of sensitivity analysis. A computer-aided analysis system was also established to design cam profiles with finite harmonic frequency so that resonance can be avoided by having harmonic frequencies less than the natural frequency of mechanical structure [5].

The dynamic cam characteristics analysis began in the 1950s. With the assistance of rising technology of digital computation, analysis and verification of dynamic characteristics computer simulations became possible. Matthew and 


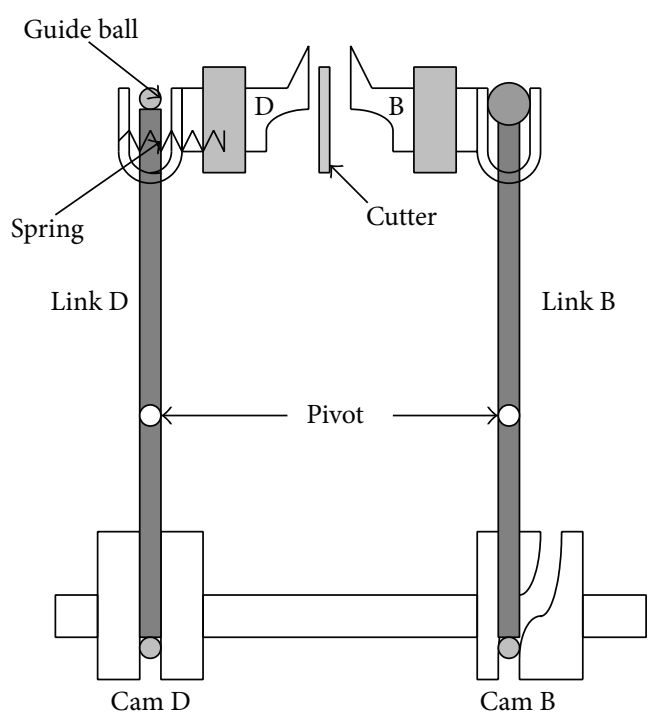

FIGURE 1: Schematic cam-driven fixture system.

Tesar $[6,7]$ applied a single degree-of-freedom mass-springdamper system to model a cam system and characterized dimensionless indexes for different speed. The concept of the primary and residual spectra was also raised to explore dynamic behavior of different cam profiles [1, 8-10]. Pisano and Freudenstein [11] developed a hybrid parametric model to simulate and investigate the dynamic response of a highspeed cam-follower system in gasoline engines. It was also suggested that the lowest natural frequency of the cam mechanism should be greater than the highest frequency in acceleration spectrum of the follower to prevent the system from resonance [12].

In order to maximize profit of products, how to reduce production cost and how to increase production efficiency are two major approaches pursued by business companies. Apparently, increasing the operation speed of machinery is the most direct and efficient approach to meet the demanded productivity growth. However, increase of the working speed can bring about unexpected high-frequency dynamics, which may even cause operational failure and system malfunction. When a mechanical system runs with a high speed, deformation and vibration of components, induced by large inertia force and acceleration, become significant and cannot be easily neglected.

A cam-driven mechanical system was developed by Hon Hai Precision Industry Co., Ltd., the largest company to produce connectors, for pin assembly operation. In order to make computer-based equipment or apparatus work properly, electrical signals need to be transmitted through all kinds of connectors among peripheral devices and the computers as well as inside the computers. This pin assembly system is designed for inserting pins into the connectors. The whole process of the cam-driven pin assembly system consists of four phases: approaching, cutting, inserting, and restoring, which are driven by three cams.
The cam-driven mechanical system accomplishes the mission of pin assembly successfully with its normal speed. For the purpose of production efficiency, the operational speed of the cam-driven pin assembly system was demanded to be as high as possible. Nevertheless, when the system operates with high running speed, insertion failure is usually caused by deficiencies of pin dropping and inaccurate positioning, which brings about breakdown and bend of pins. In order to identify the actual reasons and physics behind the assembly failure, diagnosis based on displacement and force analysis as well as frequency analysis using modern measurement devices will be conducted. According to the diagnosis results, guidelines to prevent pin dropping and pin bending will be concluded and improvement on mechanical design and assembly process for future pin assembly systems can therefore be highly expected.

\section{The Cam-Driven Mechanical System}

The cam-driven mechanical system consists of B, C, and D cam subsystems controlled by AC motors. The $\mathrm{C}$ subsystem is in charge of the motion of insertion. The tasks of cutting and holding are conducted by a pair of cooperative cam systems, including both the B and D subsystems. Since the focus of this paper is on the dynamic behavior of the holding stage, the $\mathrm{C}$ cam subsystem will be excluded in the analysis.

Figure 1 shows the structure of the cam-driven mechanical system. The structures of the B and D cam subsystems are not exactly the same. The guide ball at the end of the lever $\mathrm{D}$ is smaller than the width of its corresponding U-type guide. In addition, the U-type guide is pulled by a pretensed spring. All these designs can release the impact force caused by contact between fixtures $\mathrm{B}$ and $\mathrm{D}$ and provide a clamping force so that the fixture D always closely contacts with the cutter once they meet each other. Displacement profiles for 

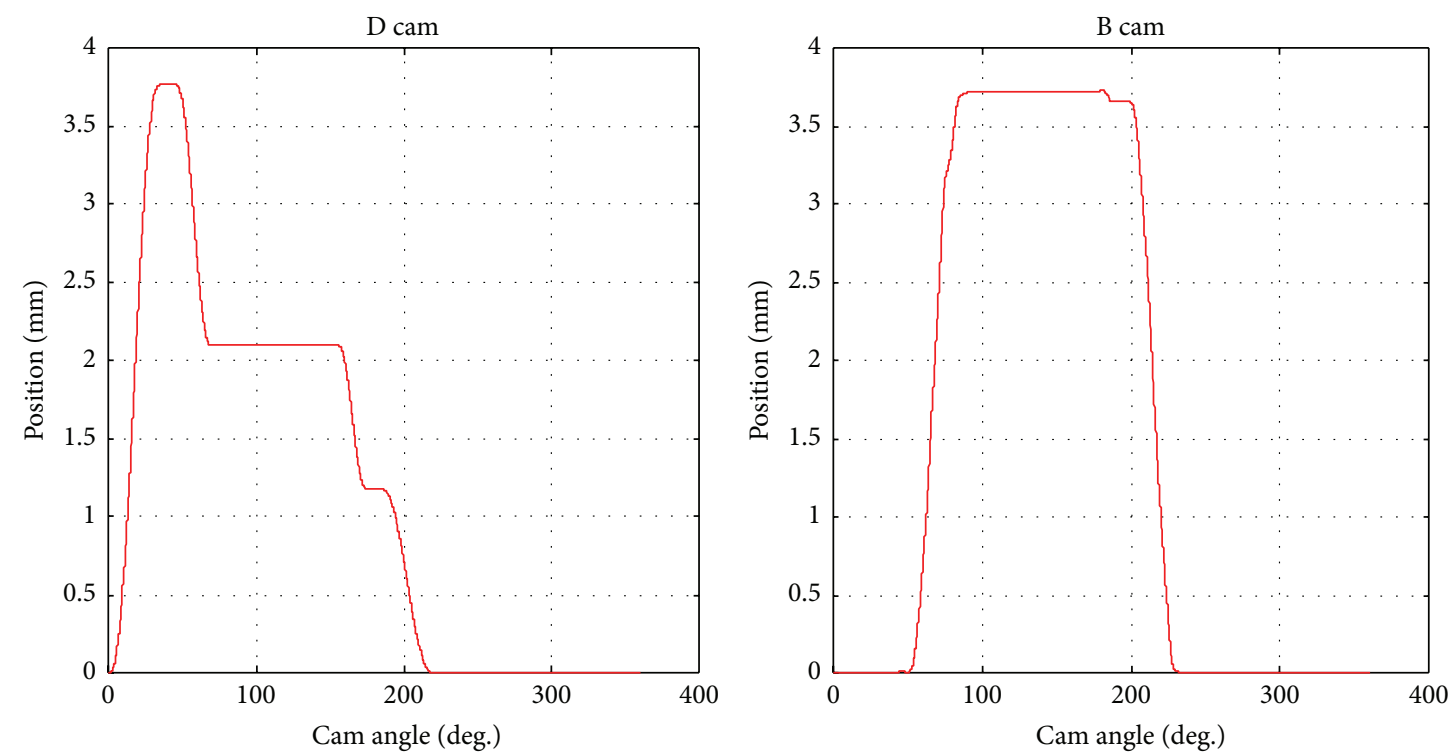

Figure 2: Displacement profiles of fixtures D and B.
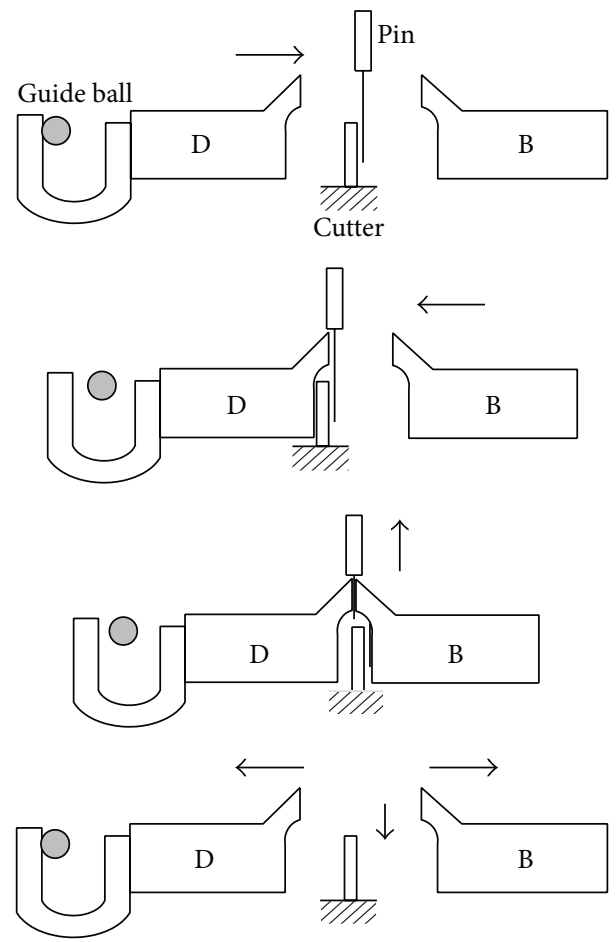

FIGURE 3: Handling process of the cam-driven fixture system.

both fixtures B and D are depicted in Figure 2. It should be noted that the displacement profile of the fixture $\mathrm{D}$ does not reflect the actual shape profile of the cam D.

The whole handling process is illustrated in Figure 3 and can be described by the following four stages:

(1) At the beginning, both fixtures B and D locate at the right-most and left-most end positions, respectively. The fixture D starts moving toward the cutter.
(2) The fixture D meets the cutter at one half of its total procession, which is about $2 \mathrm{~mm}$. Then, the fixture is separated from the lever D and firmly contacts with the cutter by the spring. Because the cutter is in the fixture's way, the fixture D therefore cannot move further and stays at its contact position. Nevertheless, the lever D keeps moving to the right due to clearance between the U-type guide and the guide ball. As a result, the behavior of the fixture $\mathrm{D}$ has nothing to do 


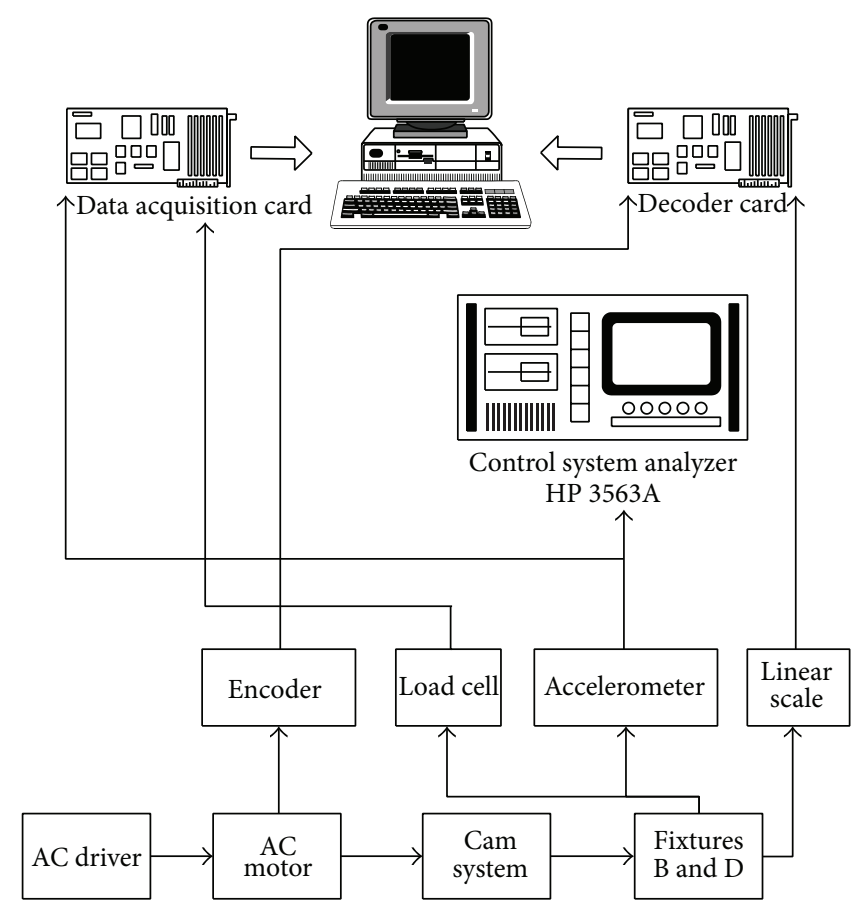

FIGURE 4: Experimental setup.

with the movement of the cam D. At the same time, the fixture B starts approaching toward the center.

(3) When both fixtures contact each other at the center and clamp a pin, the fixture B further pushes the fixture D backward to perform the cutting task. Then the pin is gripped by the fixture system and waits for the stage of insertion driven by another cam.

(4) After the insertion process is completed, both fixtures are drawn back to the original end positions and anticipate for the next working cycle. In the meantime, the spring is elongated caused by the outward movement of the guide ball. The resulting pretension is then ready for pulling the fixture $\mathrm{D}$ during the next cycle.

It appears that the cam-driven fixture system works properly for nominal operating speed. However, when the production efficiency tends to be improved by increasing the speed, insertion failure due to pin dropping and pin bending occurs. Diagnosis is therefore pursued to clarify the physical reasons for these outcomes. Some solutions that tackle these problems will also be expected to be raised for improvement of future mechanical design.

\section{Displacement and Force Analysis}

In order to acquire system responses to identify actual behavior of the pin assembly system, the experimental layout was established as shown in Figure 4. An accelerator in cooperation with an HP 3563A control system analyzer measures the dynamic characteristics of the mechanical system in terms of frequency responses. A linear scale accurately detects displacement information of both fixtures B and D. To justify the magnitude of the clamping force exerted by the fixture on the pin, a load cell was also installed. A decoder interface card resolves the rotation angle of the cams.

Experiments were conducted with different operation speeds. Two chosen conditions, $120 \mathrm{rpm}$ and $240 \mathrm{rpm}$, are presented in this paper. The displacements of both fixtures $\mathrm{B}$ and $\mathrm{D}$ and the clamping forces experienced by the fixture system were measured and are displayed in Figures 5 and 6, respectively. It should be mentioned here that these curves shown in the figures are raw data and the time references for all plots do not correspond to one another.

In Figure 5, a little cutback is found in the displacement of the fixture B before it retracts to its original position. At that instant, the fixture B collides with the fixture D and is pushed backwards a little. It appears that the fixture D meets the cutter approximately at the distance of $2.4 \mathrm{~mm}$. Besides, two dwell periods are observed in the displacement profile of D. The first one is used to wait for the fixture B to accomplish the cutting task. The insertion is then performed during the second dwell duration.

Figure 6 clearly shows that a high impulse force is induced by the collision of those two fixtures. Furthermore, the magnitude of the impact force grows when the operation speed increases. Immediately after that, a flat region indicates the clamping force exerted by the fixture system. However, it is interesting to note that the range of the clamping force reduces when the operation speed is doubled. Explanation of this effect will be provided in the next section. The first pulse of the curve for the cam D implies the force variation caused by the contact between the fixture $\mathrm{D}$ and the cutter. 

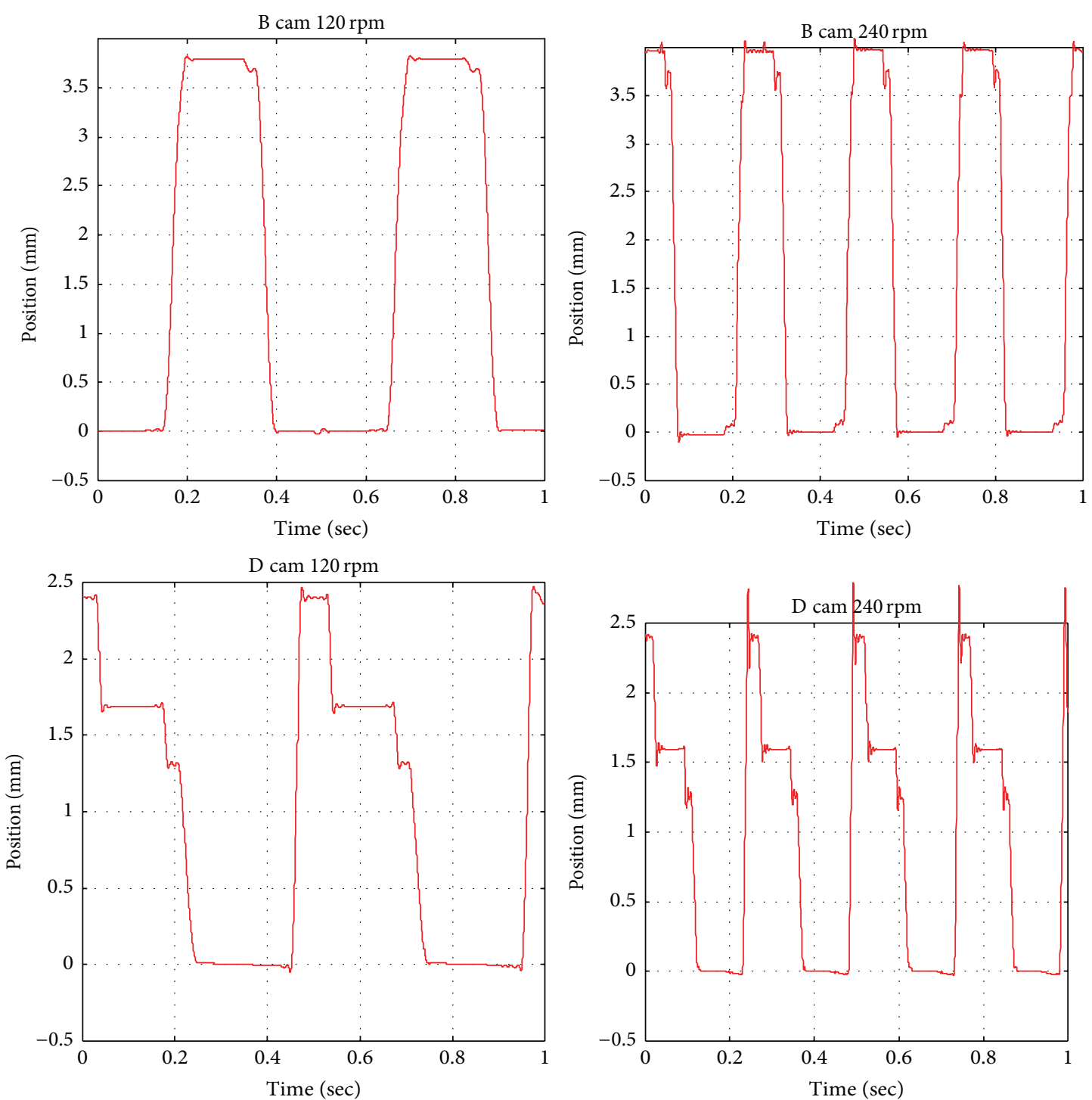

FIGURE 5: Displacements of the fixtures B and D for two different speeds.

Figure 5 also indicates that the maximum displacement of the fixtures $B$ grows while the working speed increases. In the meanwhile, the fixture D's position reduces. In other words, the clamped position is deviated and failure of pin assembly may result. This phenomenon can also be demonstrated with the assistance of Figure 7. It was found that large friction exists between the moving parts of the fixture and the corresponding guide. During the climbing stage, both the fixture B and the lever B have the same tendency of deformation indicated at the position (1). However, when the cam reaches the dwell phase, the lever will be back to the position (3) instead of the original location (4) due to the effect of friction. As a result, a position deviation occurs. For higher operation speed, greater inertia force is capable of overcoming the friction and smaller position deviation will be caused. The fixture B then tends to move toward the fixture D. Consequently, inaccurate insertion position may result. The above description also gives the reason why the exerted force on the fixture B reduces at the clamping stage for high operation speed. Since limited lever's deformation happens for high speed, the force applied to the fixture becomes smaller.

The contact oscillation during the clamping stage also influences the assembly performance of the pin assemble system. Apparently, higher operation speed is always accompanied by more significant vibration. Based on the measurements shown in Figure 5, the oscillation amplitude of the fixture $\mathrm{D}$ is about $0.2 \mathrm{~mm}$ for $180 \mathrm{rpm}$ operation speed, which is already greater than the width of the pin, $0.15 \mathrm{~mm}$. So the result of pin dropping is highly expected for that working speed.

\section{Frequency Analysis}

Frequency analysis was conducted to acquire the system's dynamic behavior in terms of the frequency via a spectrum 

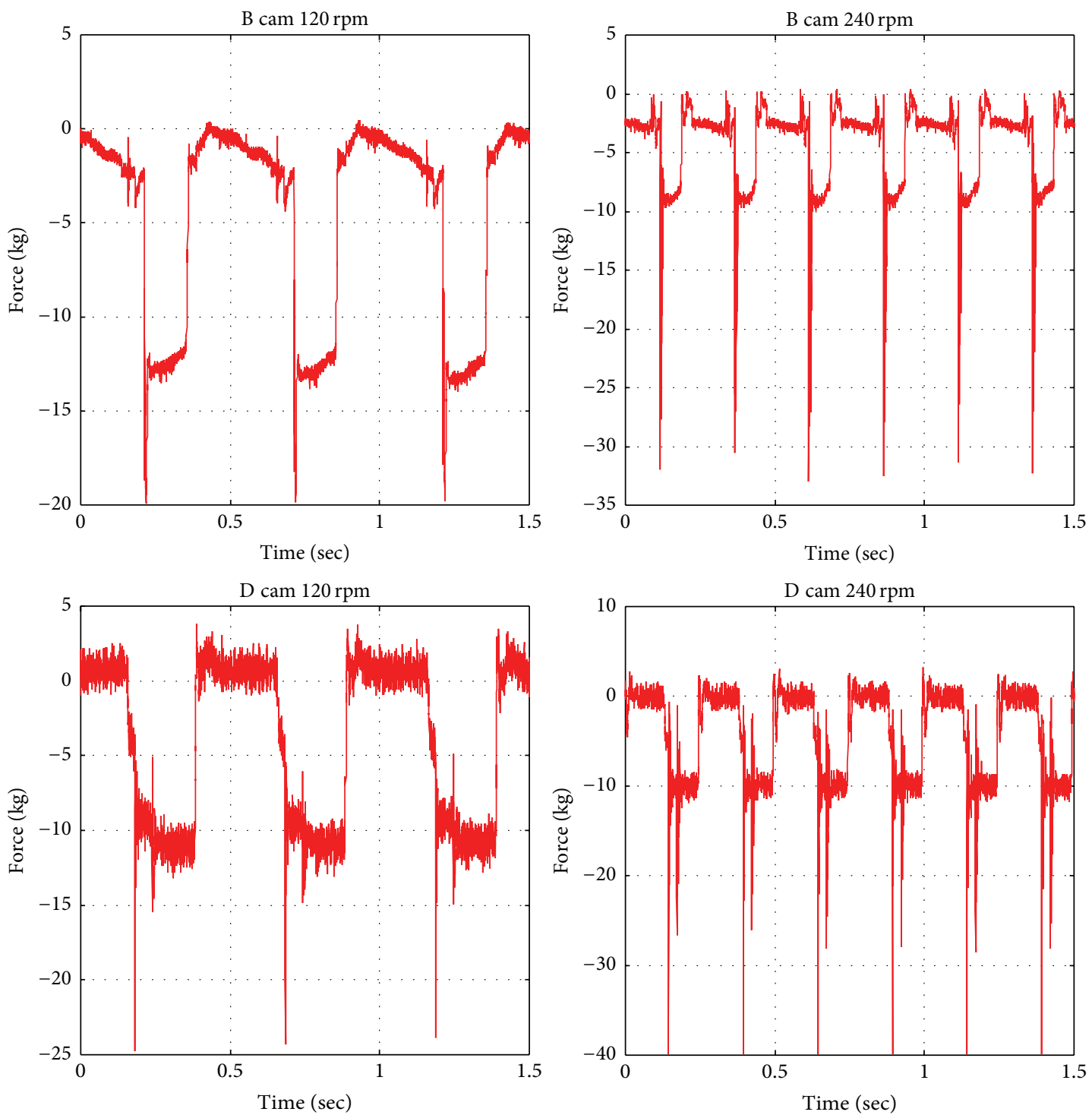

FIgURE 6: Forces experienced by the fixtures B and D for two different speeds.

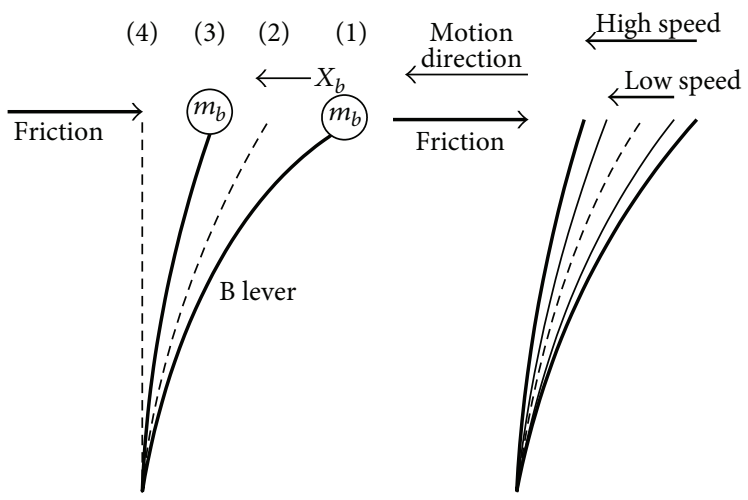

FIGURE 7: Illustrative representation of lever deformation. 

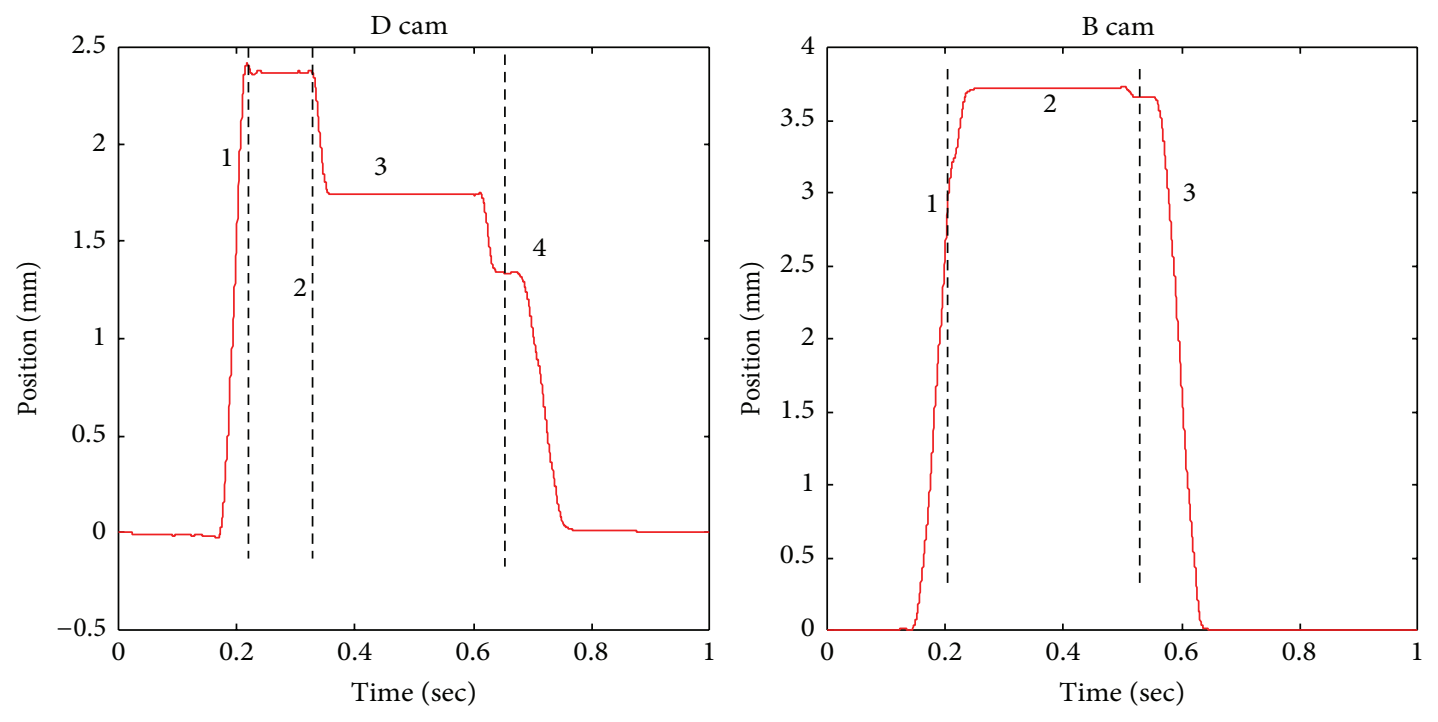

FIGURE 8: Segmentation of displacement profiles for system identification.

analyzer and the technique of system identification. The spectrum analyzer directly reflects actual frequency characteristics of the pin assembly system. However, the results of system identification provide mathematical models of the system, which can be applied for further design modification and performance analysis. Because of complexity of the dynamic behavior of the cam-driven pin assembly system, the task of frequency analysis was performed piecewise. The displacement profiles of the fixtures $\mathrm{B}$ and $\mathrm{D}$ are divided into three and four sections, respectively, as illustrated in Figure 8.

The first and the third sections of the fixture $B$ and the first and the fourth sections of the fixture $\mathrm{D}$ are collision-free and can be approximated by linear responses. Furthermore, both inputs and outputs for these regions are measurable. Based on actual experiment measurements, Figures 9 and 10 present the Bode plots for the fixture B at sections 1 and 3 and the fixture $\mathrm{D}$ at sections 1 and 4 for two different operation speeds.

From those figures, the natural frequency apparently increases for high operation speeds. This phenomenon of variable natural frequency should not happen in linear systems. Therefore, a reasonable judgment for this observation would be existence of unmodeled nonlinearity. Through extensive modelling and comparisons between simulations and experimental results, the major nonlinear effect was found to be the backlash occurring at the U-type guide on the lever B. In other words, the U-type guide can be modelled as shown in Figure 11. A brief exploration regarding varying natural frequency with respect to the backlash will be given in the following paragraphs.

Assume the total deflection $\Delta \delta$ is the sum of the linear deformation $\Delta x$ caused by elasticity of mechanical components and an error $\Delta c$ because of unknown nonlinear attributes; that is,

$$
\Delta \delta=\Delta x+\Delta c
$$

The nonlinear error $\Delta c$ due to backlash is reasonably assumed to be a positive constant and independent of the speed. Therefore, regardless of the nonlinear effect, the linear dynamic equations for low and high operation speeds can be established as

$$
\begin{gathered}
F_{L}=K \Delta x_{L}, \\
F_{H}=K \Delta x_{H},
\end{gathered}
$$

where $K$ denotes the system stiffness, which is a fixed constant, and the subscripts of $L$ and $H$ individually represent physical variables at low and high speeds. But when a backlash nonlinearity exists, the above expressions become

$$
\begin{gathered}
F_{L}=K_{L}\left(\Delta x_{L}+\Delta c\right), \\
F_{H}=K_{H}\left(\Delta x_{H}+\Delta c\right),
\end{gathered}
$$

where $K_{H}$ and $K_{L}$ are identified stiffness for high and low speeds, respectively, using linear system identification techniques. Subtracting (3) from (4) and incorporating (2) into the above result yield

$$
K_{H}-K_{L}=\frac{K \Delta c\left(\Delta x_{H}-\Delta x_{L}\right)}{\left(\Delta x_{H}+\Delta c\right)\left(\Delta x_{L}+\Delta c\right)} .
$$

Since larger mechanical deformation occurs for higher operation speed, that is, $\Delta x_{H}>\Delta x_{L}$, it can be concluded that $K_{H}>K_{L}$ for positive $\Delta c$. In other words, the identified stiffness constant for high speed becomes greater than that for low operation speed. The above derivation explains the phenomenon of frequency drift when linear modeling techniques are employed to the system that contains backlash nonlinear property.

In order to further explore the physics of the mechanical system and to conduct future system modification and improvement, mathematical models of the cam-driven pin 

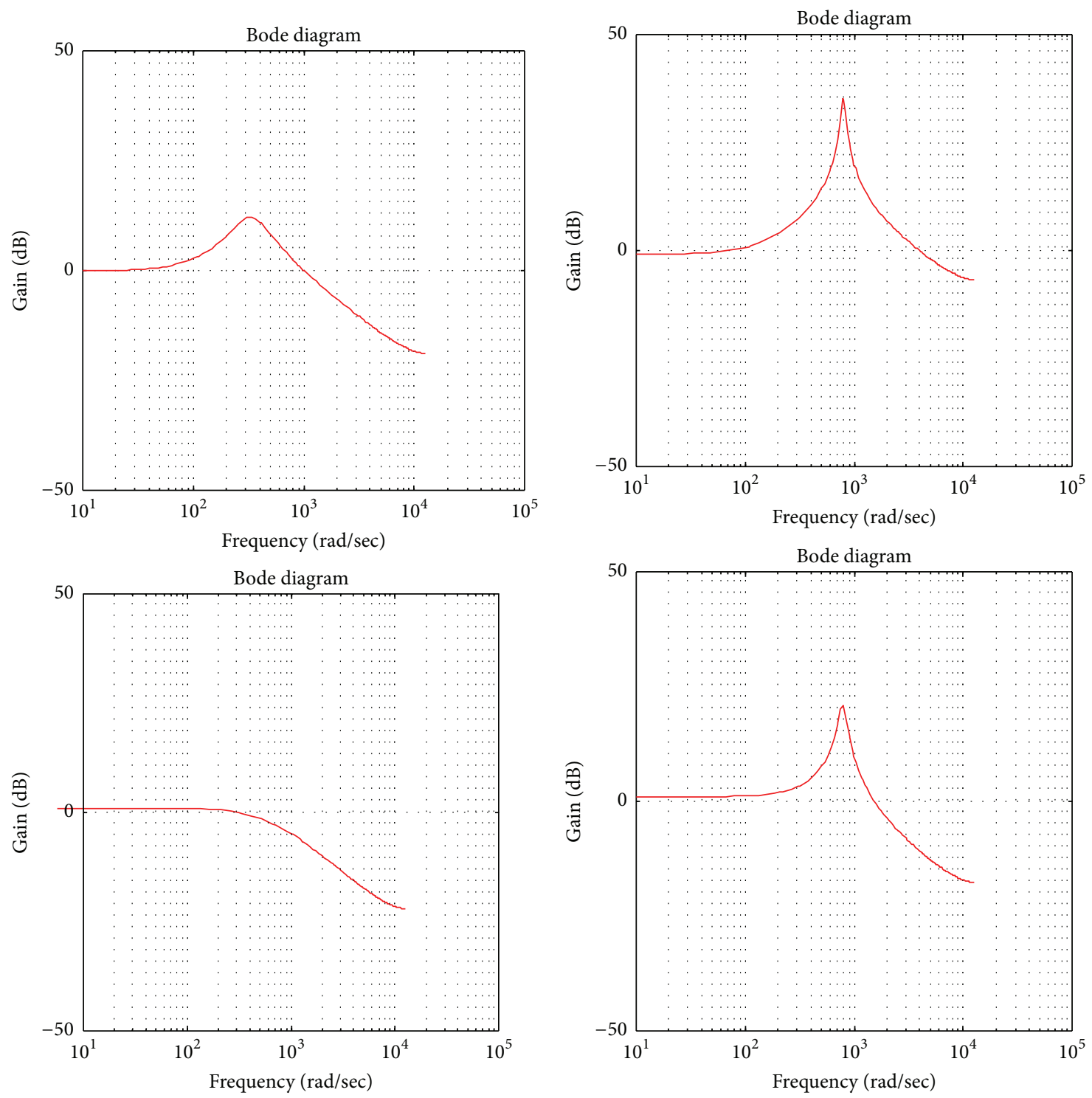

(a)

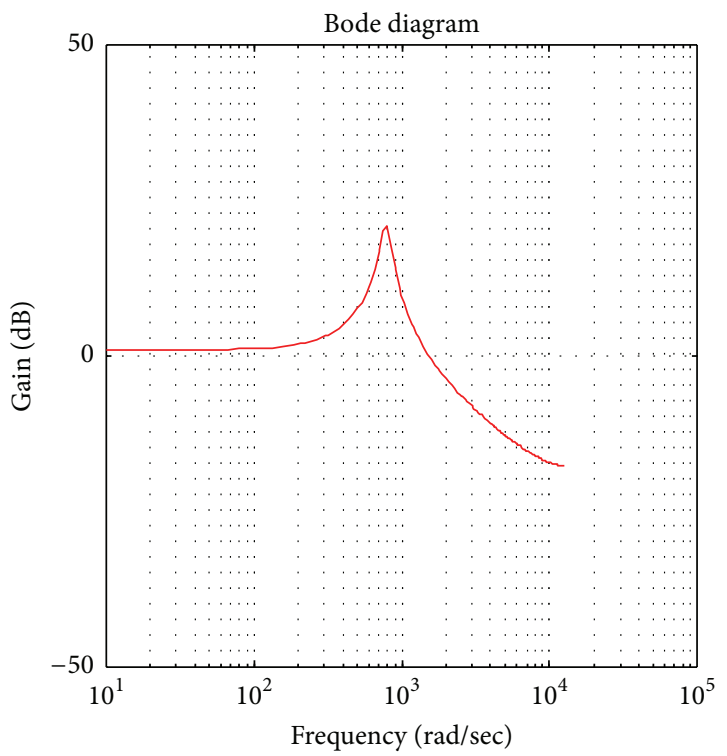

(b)

FIgURE 9: Bode plots for the fixture B at sections 1 and 3 for $120 \mathrm{rpm}$ (a) and $240 \mathrm{rpm}$ (b).

assembly system need to be established first. The mechanical system appears to be too complicated to be analyzed by traditional free body diagram approach. Therefore, the technique of system identification was chosen.

Linear system identification has been a matured technique to build a mathematical model from actual input and out responses of the target system [13-15]. The ARMAX (autoregressive moving average exogenous) model was chosen to fit the first and the third sections of the fixture $B$ and the first and the fourth sections of the fixture D. All other portions of the profiles then were identified using the ARMA technique because of difficulty in input measurement during collision stages. Orders of the resulting transfer function models were judged by the famous AIC (Akaike Information Criterion) method. Autocorrelation and cross-correlation of residuals were also examined to make sure that the selected models were independent with input signals. In addition, coherence function analysis was also conducted to verify the credibility of the resulting transfer function models. The resulting transfer functions can be expressed in the following forms:

$$
y_{k}=\frac{B\left(z^{-1}\right)}{A\left(z^{-1}\right)} u_{k}+\frac{C\left(z^{-1}\right)}{A\left(z^{-1}\right)} w_{k} \text {, }
$$

where $u_{k}, y_{k}$, and $w_{k}$ represent the input signal, the output signal, and a random white noise, respectively.

Tables 1 and 2 list the resulting polynomials $A\left(z^{-1}\right)$, $B\left(z^{-1}\right)$, and $C\left(z^{-1}\right)$ of the identified system models for $120 \mathrm{rpm}$ and $240 \mathrm{rpm}$ operation speeds, respectively. Performance of system identification was examined by comparison of dynamic behavior between actual experimental data and 

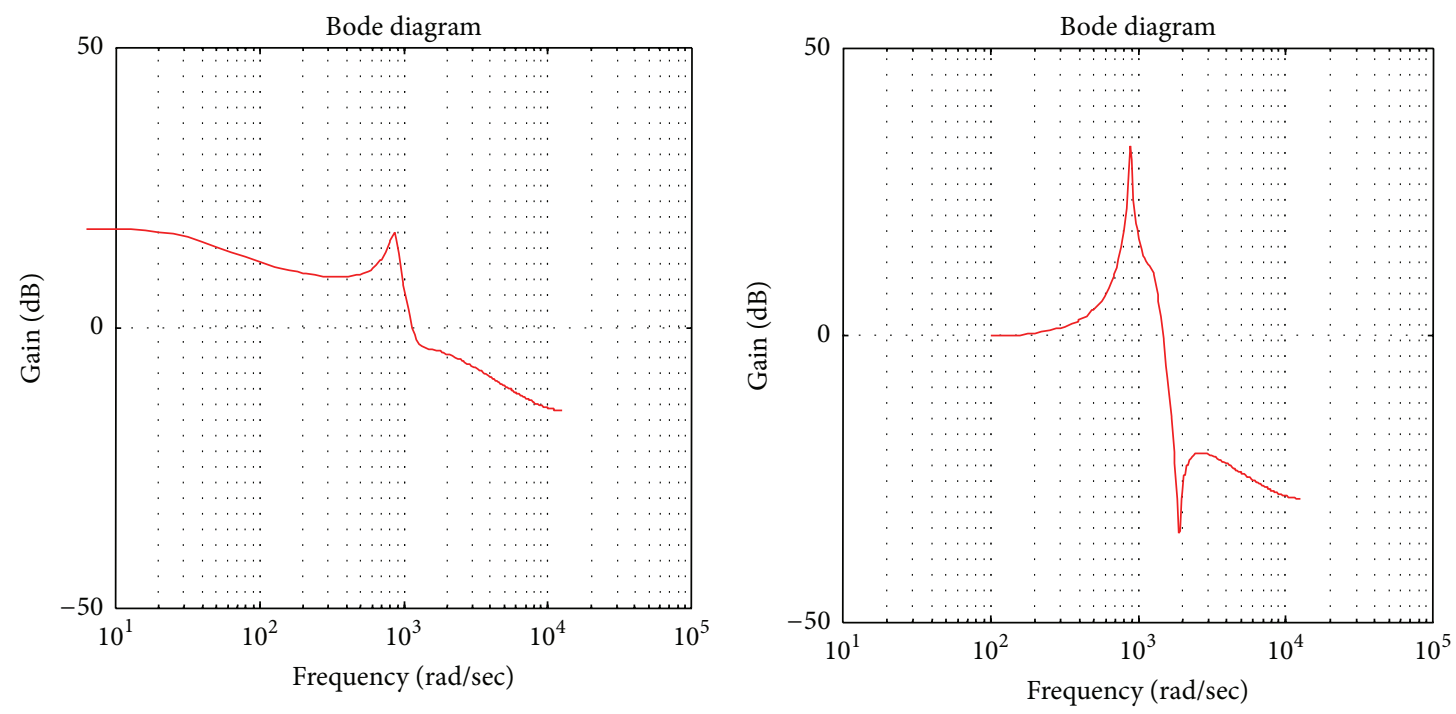

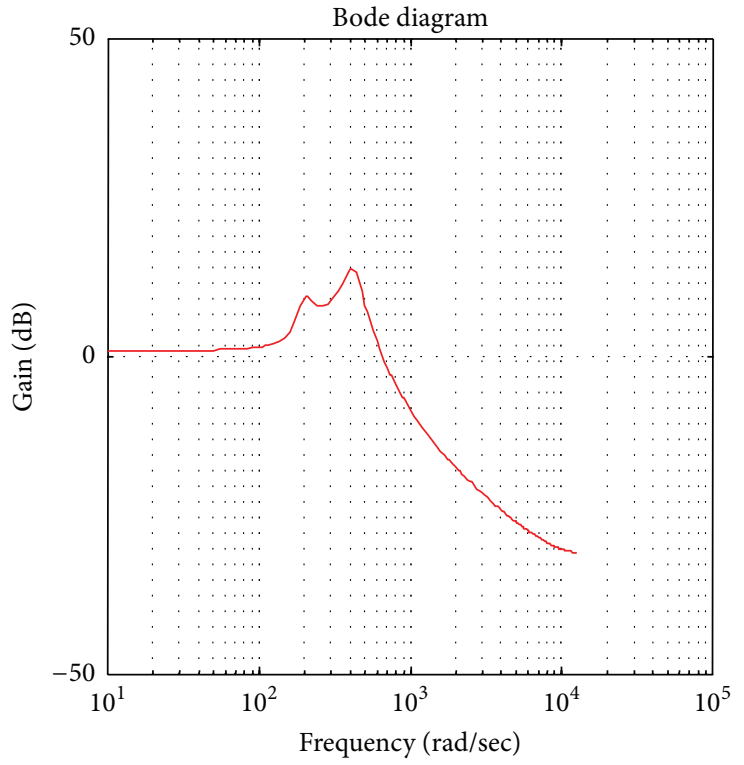

(a)

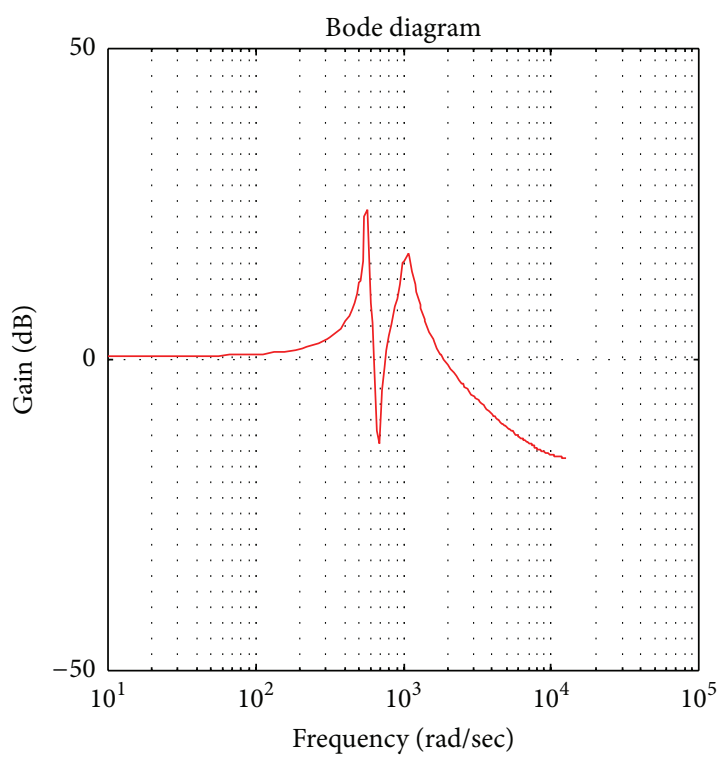

(b)

FIgURE 10: Bode plots for the fixture D at sections 1 and 4 for $120 \mathrm{rpm}$ (a) and $240 \mathrm{rpm}$ (b).

TABLE 1: Results of system identification for the subsystem B.

\begin{tabular}{lccc}
\hline Sections & & \multicolumn{2}{c}{ Operation speed (rpm) } \\
& & 120 & $1-1.9766 z^{-1}+1.0159 z^{-2}$ \\
1 & $A\left(z^{-1}\right)$ & $1-1.9852 z^{-1}+0.9891 z^{-2}$ & $0.9357 z^{-1}-0.9005 z^{-2}$ \\
& $B\left(z^{-1}\right)$ & $0.0513 z^{-1}-0.0473 z^{-2}$ & $1+0.9838 z^{-1}$ \\
\hline & $C\left(z^{-1}\right)$ & $1+0.9899 z^{-1}$ & $1-0.9621 z^{-1}$ \\
2 & $A\left(z^{-1}\right)$ & $1-0.9885 z^{-1}$ & - \\
& $B\left(z^{-1}\right)$ & - & $1+0.7991 z^{-1}$ \\
\hline & $C\left(z^{-1}\right)$ & $1+0.8597 z^{-1}$ & $1-1.9334 z^{-1}+0.9766 z^{-2}$ \\
3 & $A\left(z^{-1}\right)$ & $1-1.8638 z^{-1}+0.8642 z^{-2}$ & $-0.2366 z^{-1}+0.2778 z^{-2}$ \\
& $B\left(z^{-1}\right)$ & $0.1482 z^{-1}-0.1477 z^{-2}$ & $1+0.9064 z^{-1}$ \\
\hline
\end{tabular}




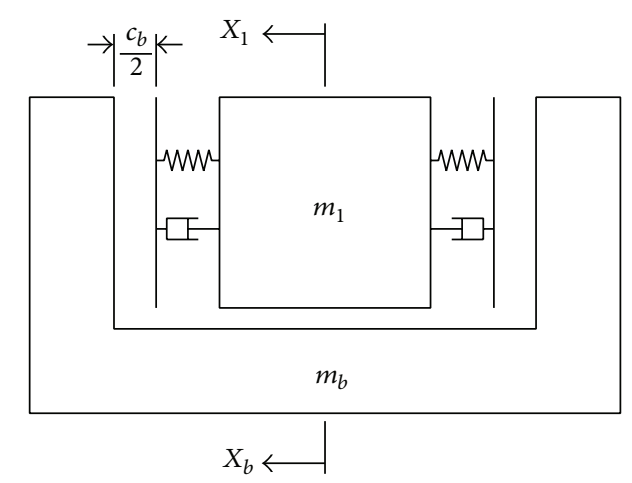

FIGURE 11: Modeling of the U-type guide with backlash.

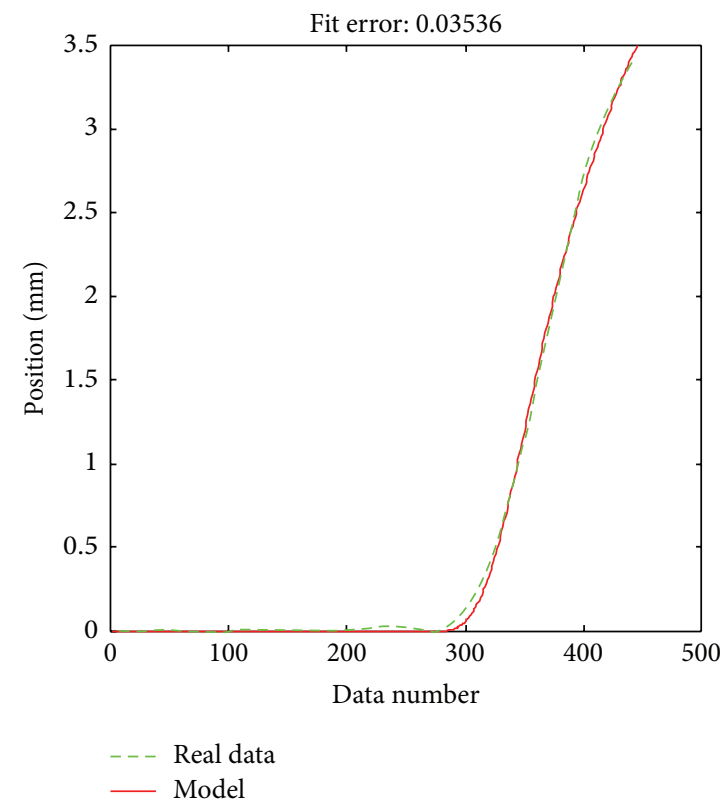

(a)

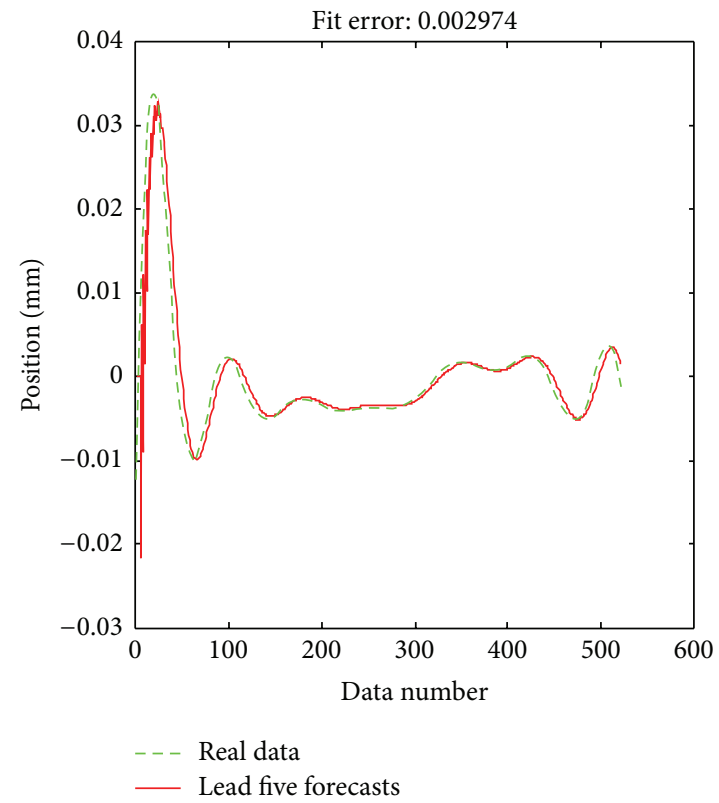

(b)

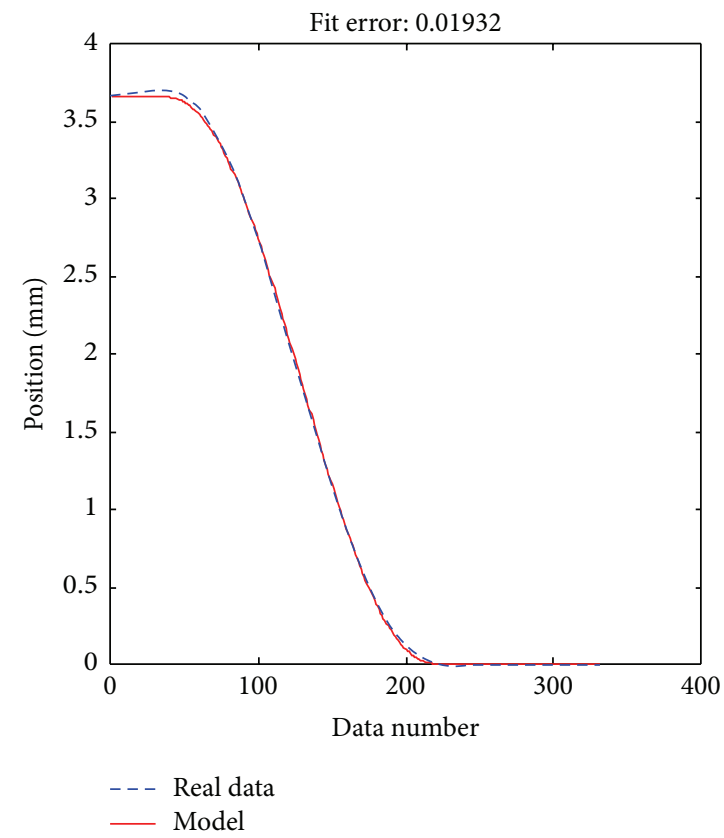

(c)

FIGURE 12: Model verification for the subsystem B for $120 \mathrm{rpm}$ operation speed: (a) section 1, (b) section 2, and (c) section 3. 


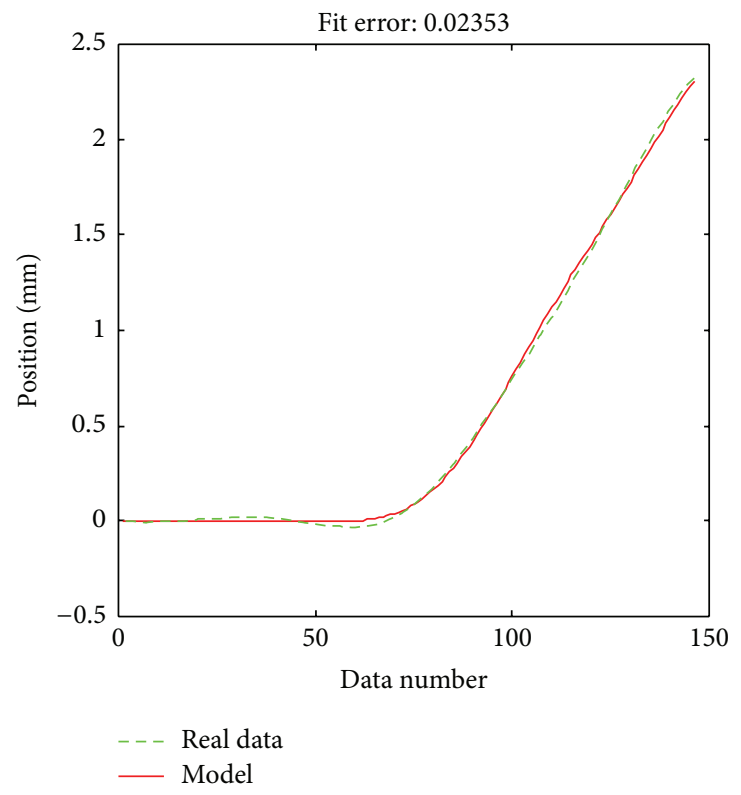

(a)

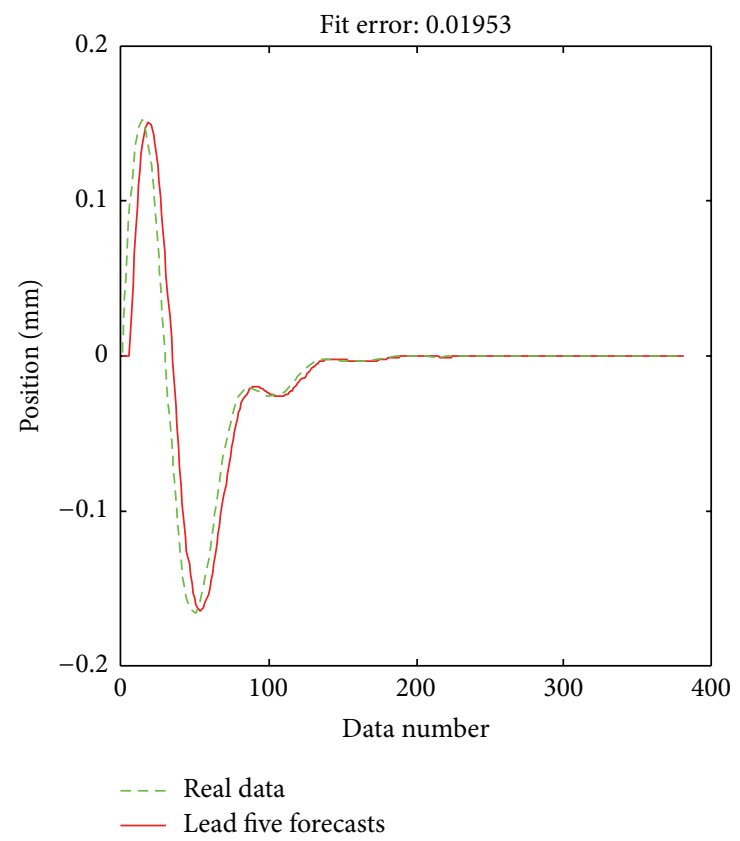

(c)

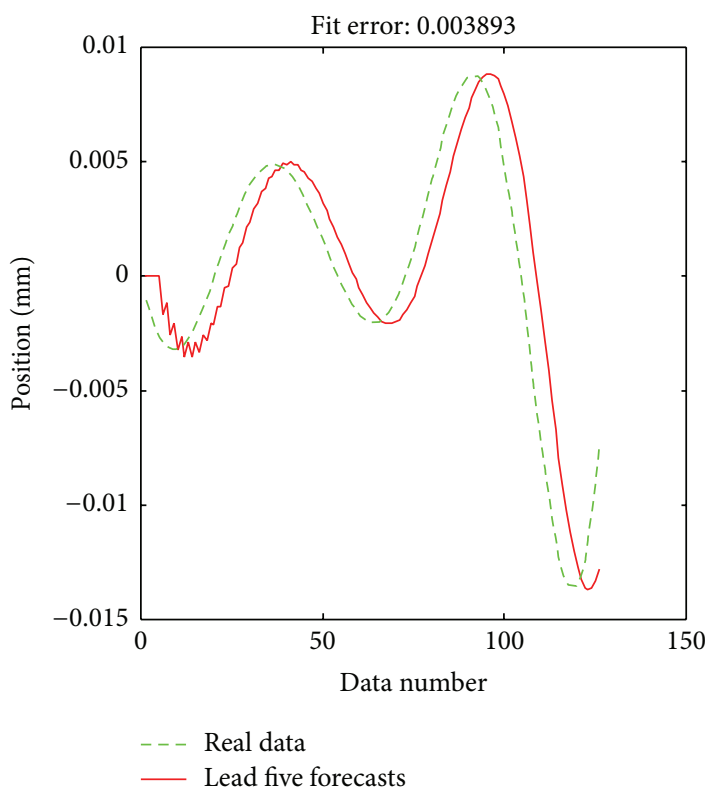

(b)

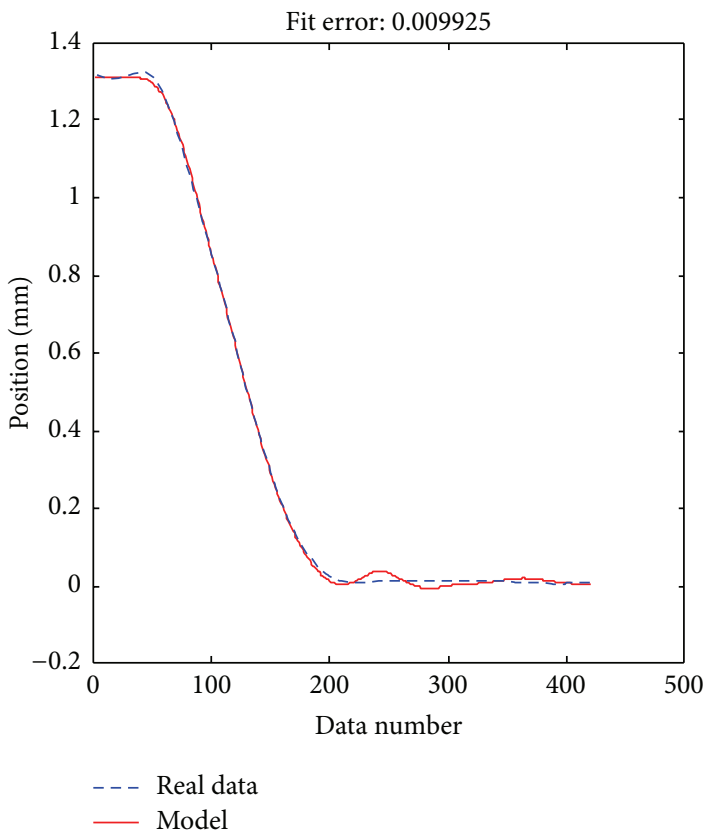

(d)

FIGURE 13: Model verification for the subsystem D for $120 \mathrm{rpm}$ operation speed: (a) section 1, (b) section 2, (c) section 3, and (d) section 4.

dynamic response generated by identified model. Satisfactory results of model verification for the fixture systems B and $\mathrm{D}$ at $120 \mathrm{rpm}$ operation speed are, respectively, illustrated in Figures 12 and 13. Due to inherent characteristics of the ARMA model, model responses for the section 2 of the fixture $\mathrm{B}$ and the sections 2 and 3 of the fixture $\mathrm{D}$ are demonstrated by the lead five forecasts. Similar model verification results for the fixture systems B and D at $240 \mathrm{rpm}$ are also depicted in Figures 14 and 15. Based on the mathematical models obtained from the process of system identification, detailed system properties can be fully understood and prediction of the system responses becomes highly possible.

\section{Conclusions}

Based on the above study and analysis, the physics behind the phenomenon of pin dropping and inaccurate positioning for the cam-driven pin assembly system running with a high 


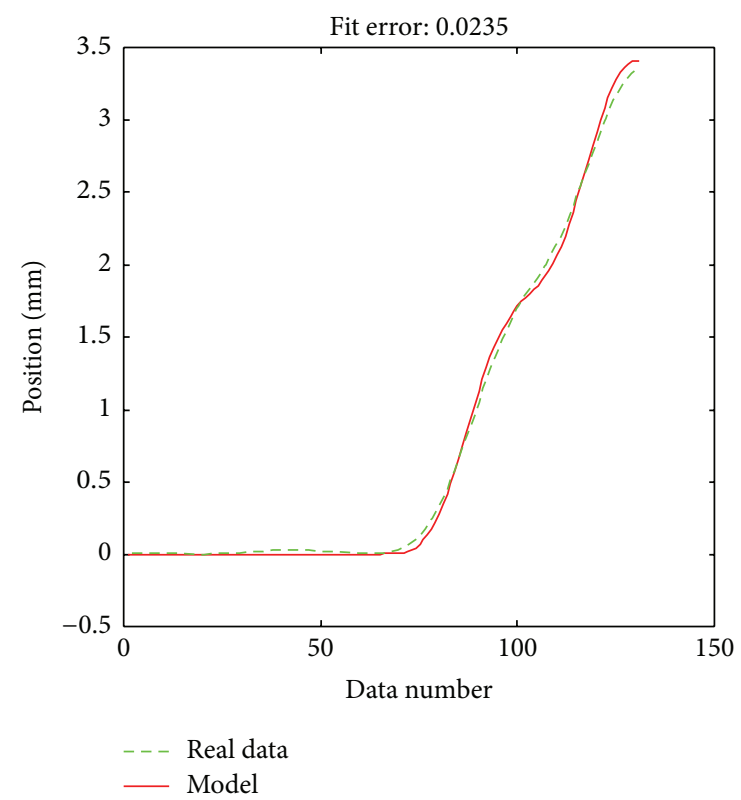

(a)

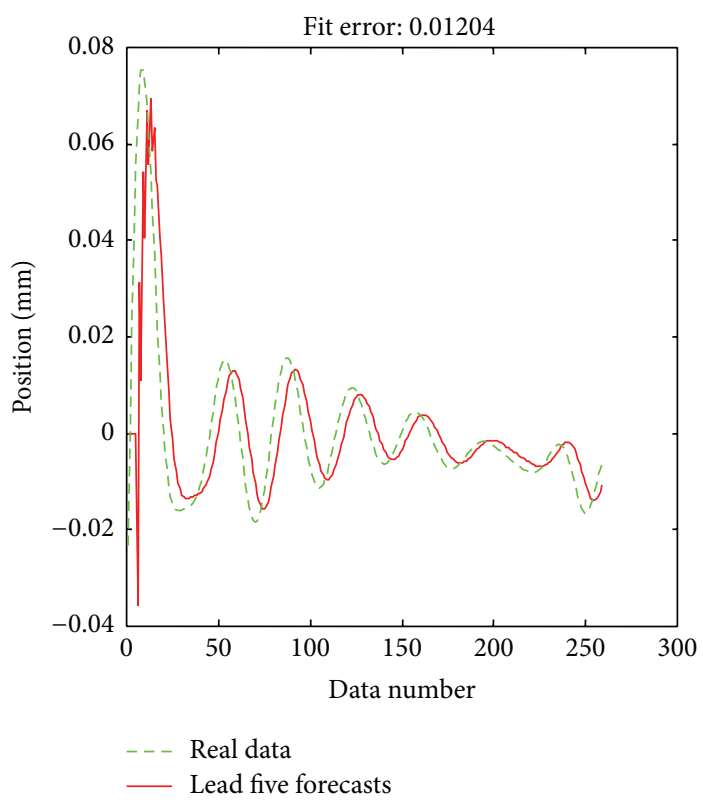

(b)

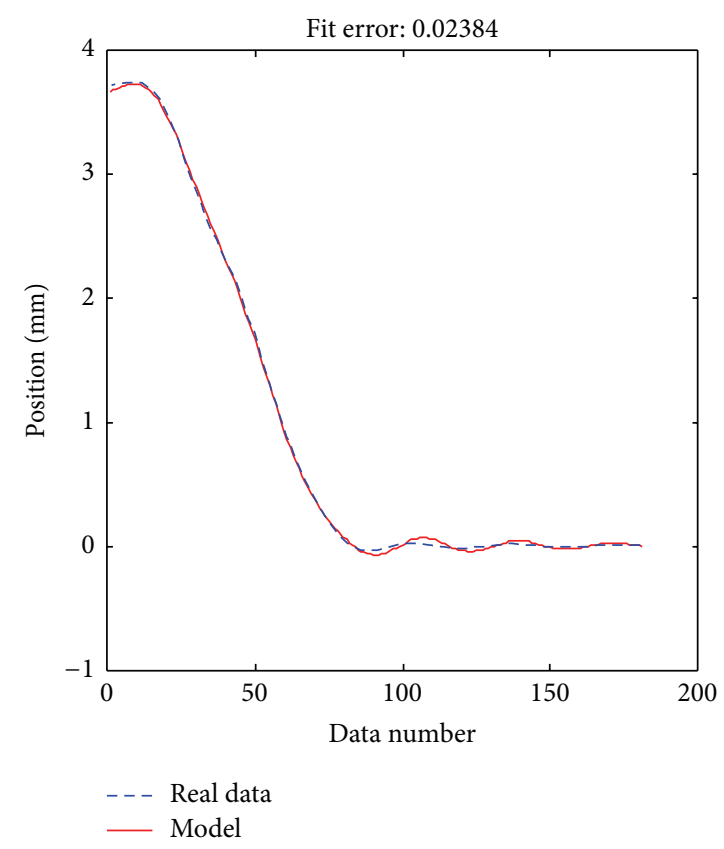

(c)

FIGURE 14: Model verification for the subsystem B for $240 \mathrm{rpm}$ operation speed: (a) section 1, (b) section 2, and (c) section 3.

speed is presented. Results of frequency analysis indicate greater natural frequency and system stiffness caused by nonlinear dynamics for higher operation speed. According to measurements of experiments, the malfunctions of pin dropping and false pin's position for insertion assembly are mainly resulting by contact oscillation of moving components and deviation of the locked pin's location, respectively. It appears that the clamping force is reduced and drift of the locked pin's location is induced for higher running speed. In addition, separation of the pin assembly system induced by contact oscillation generates clearance larger than the width of the pin.

Less oscillation can be reached by the following approaches:

(1) Increase the stiffness of the pretensioned spring to suppress vibrations.

(2) Reduce the mass of the fixture components to lower the inertia force caused by contact collision. 


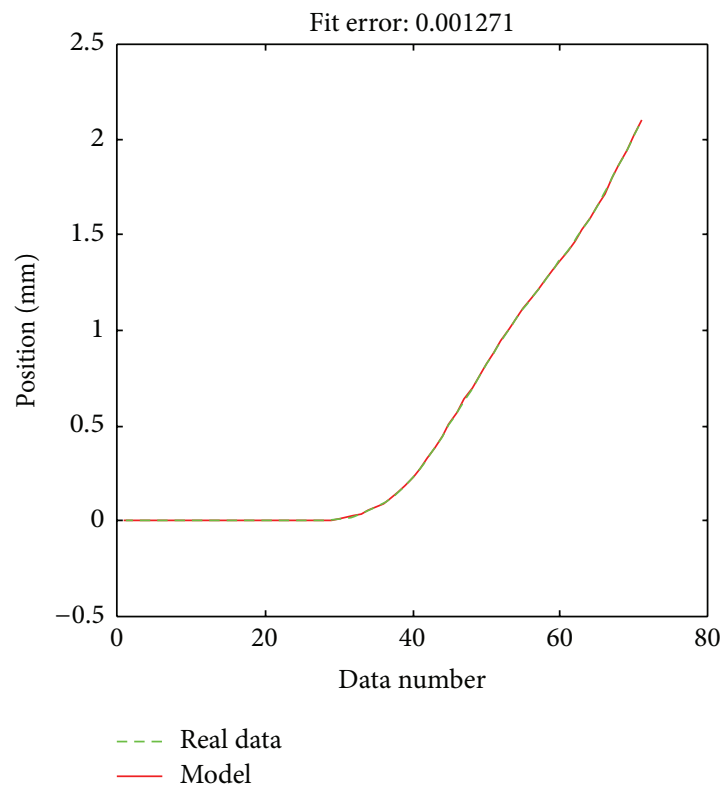

(a)

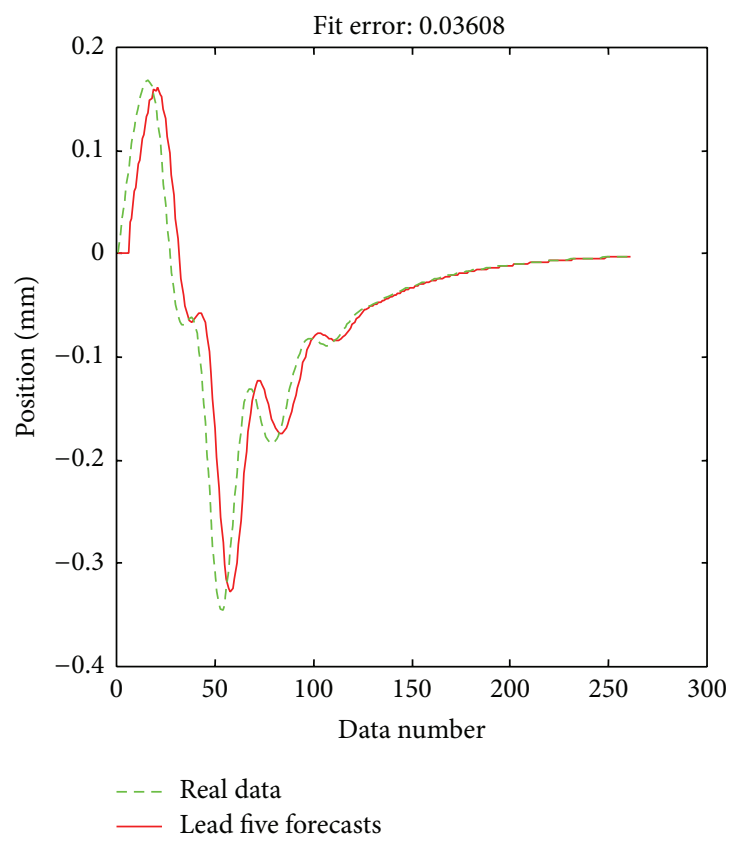

(c)

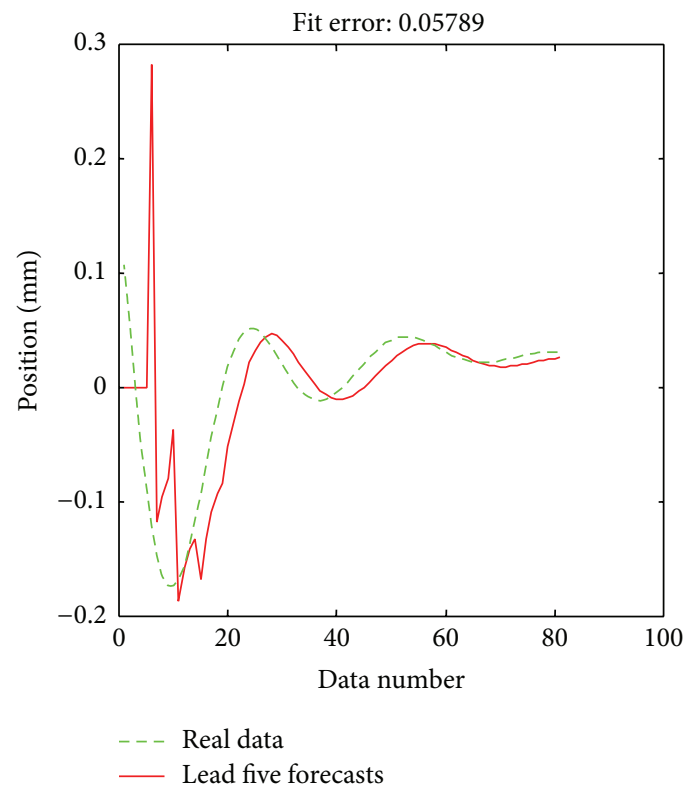

(b)

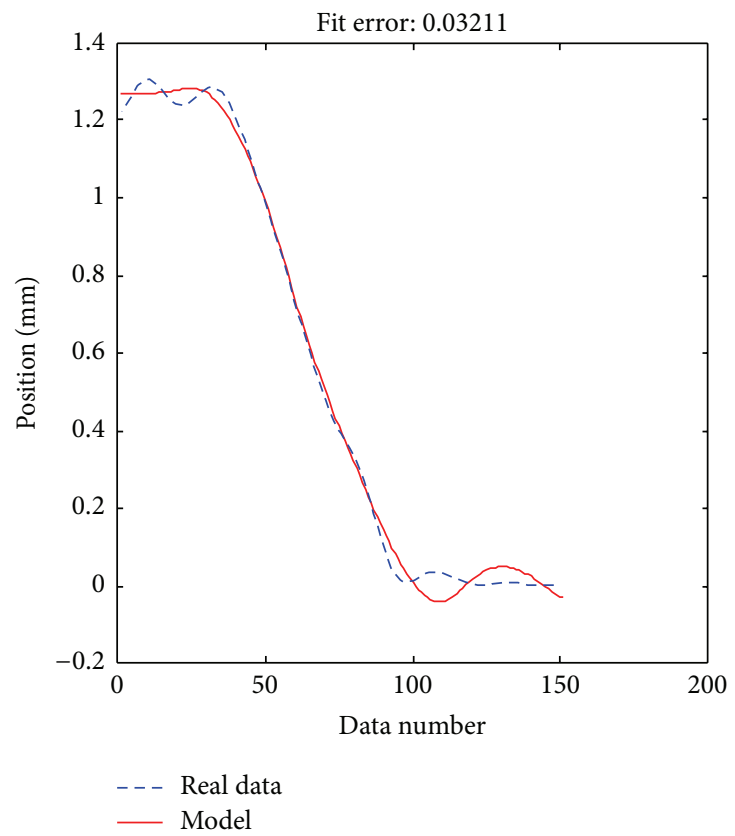

(d)

Figure 15: Model verification for the subsystem D for $240 \mathrm{rpm}$ operation speed: (a) section 1, (b) section 2, (c) section 3, and (d) section 4.

(3) Increase the friction of the guide to rapidly attenuate vibrations.

(4) Modify the cam profiles to decrease the speed and acceleration during the contact.

Inaccurate insertion location is caused by position deviation of the fixture B. A number of methods improving this effect are summarized as follows:
(1) Increase the stiffness of the lever.

(2) Reduce the friction of the guide.

(3) Minimize the backlash.

It appears that some contradictions exist for the above solutions. How to gain the most benefit from the trade-off between two opposite modification strategies needs further analysis and judgment. 
TABLE 2: Results of system identification for the subsystem D.

\begin{tabular}{|c|c|c|c|}
\hline \multirow{2}{*}{ Sections } & & \multicolumn{2}{|c|}{ Operation speed (rpm) } \\
\hline & & 120 & 240 \\
\hline \multirow{3}{*}{1} & $A\left(z^{-1}\right)$ & $1-3.954 z^{-1}+5.879 z^{-2}-3.894 z^{-3}+0.967 z^{-4}$ & $1-3.793 z^{-1}+5.379 z^{-2}-3.682 z^{-3}+0.943 z^{-4}$ \\
\hline & $B\left(z^{-1}\right)$ & $0.087 z^{-1}-0.0249 z^{-2}+0.238 z^{-3}-0.0766 z^{-4}$ & $0.0851 z^{-1}-0.216 z^{-2}-0.2 z^{-3}-0.0642 z^{-4}$ \\
\hline & $C\left(z^{-1}\right)$ & $1+0.807 z^{-1}$ & $1+0.924 z^{-1}$ \\
\hline \multirow{3}{*}{2} & $A\left(z^{-1}\right)$ & $1-1.0005 z^{-1}$ & $1-0.96 z^{-1}$ \\
\hline & $B\left(z^{-1}\right)$ & - & - \\
\hline & $C\left(z^{-1}\right)$ & $1+0.9382 z^{-1}$ & $1+0.905 z^{-1}+0.72 z^{-2}+0.454 z^{-3}$ \\
\hline \multirow{3}{*}{3} & $A\left(z^{-1}\right)$ & $1-0.9964 z^{-1}$ & $1-0.9876 z^{-1}$ \\
\hline & $B\left(z^{-1}\right)$ & - & - \\
\hline & $C\left(z^{-1}\right)$ & $1-0.2161 z^{-1}$ & $1+0.9099 z^{-1}$ \\
\hline \multirow{3}{*}{4} & $A\left(z^{-1}\right)$ & $1-3.945 z^{-1}+5.848 z^{-2}-3.861 z^{-3}+0.958 z^{-4}$ & $1-3.875 z^{-1}+5.713 z^{-2}-3.799 z^{-3}+0.962 z^{-4}$ \\
\hline & $B\left(z^{-1}\right)$ & $1+0.0635 z^{-1}-0.0176 z^{-2}+0.162 z^{-3}-0.0492 z^{-4}$ & $1-0.29 z^{-1}+0.91 z^{-2}-0.958 z^{-3}+0.319 z^{-4}$ \\
\hline & $C\left(z^{-1}\right)$ & $1-0.9418 z^{-1}$ & $1+0.8474 z^{-1}$ \\
\hline
\end{tabular}

\section{Conflict of Interests}

The authors declare that there is no conflict of interests regarding the publication of this paper.

\section{Acknowledgment}

This work was sponsored by the Hon Hai Precision Industry Co., Ltd.

\section{References}

[1] F. Y. Chen, "A survey of the state of the art of cam system dynamics," Mechanism and Machine Theory, vol. 12, no. 3, pp. 201-224, 1977.

[2] H.-S. Jeon, K.-J. Park, and Y.-S. Park, "An optimal cam profile design considering dynamic characteristics of a cam-valve system," Experimental Mechanics, vol. 29, no. 4, pp. 357-363, 1989.

[3] M. Chew, F. Freudenstein, and R. W. Longman, "Application of optimal control theory to the synthesis of high-speed camfollower systems," Journal of Mechanisms, Transmissions, and Automation in Design, vol. 105, no. 3, pp. 576-591, 1983.

[4] S.-S. D. Young and T. E. Shoup, "The sensitivity analysis of cam mechanism dynamics," ASME Journal of Mechanical Design, vol. 104, no. 2, pp. 476-481, 1982.

[5] L. Van den Noortgate and J. De Fraine, "A general computer aided method for designing high speed cams avoiding the dangerous excitation of the machine structure," Mechanism and Machine Theory, vol. 12, no. 3, pp. 237-245, 1977.

[6] G. K. Matthew and D. Tesar, "The design of modeled cam systems," Journal of Engineering for Industry-Transactions of the ASME, vol. 97, no. 4, pp. 1175-1189, 1975.

[7] G. K. Matthew and D. Tesar, "Cam system design: the dynamic synthesis and analysis of the one degree of freedom model," Mechanism and Machine Theory, vol. 11, no. 4, pp. 247-257, 1976.

[8] F. Y. Chen, "Analysis and design of cam-driven mechanisms with nonlinearities," Journal of Engineering for Industry, vol. 95, no. 3, pp. 685-694, 1973.
[9] F. Y. Chen and Y. Polvanich, "Dynamics of high-speed camdriven mechanisms," Journal of Engineering for Industry, vol. 97, no. 3, pp. 769-784, 1975.

[10] F. Y. Chen, "Assessment of the dynamic quality of a class of dwell-rise-dwell cams," Journal of Mechanical Design, vol. 103, no. 4, pp. 793-802, 1981.

[11] A. P. Pisano and F. Freudenstein, "An experimental and analytical investigation of the dynamic response of a high-speed cam-follower system," Journal of Mechanisms, Transmissions, and Automation in Design, vol. 105, no. 4, pp. 692-704, 1983.

[12] K. S. H. Sadek, J. Rosinski, and M. R. Smith, "Natural frequency of a cam mechanism," Proceedings of the Institution of Mechanical Engineers, Part C: Journal of Mechanical Engineering Science, vol. 204, no. 4, pp. 255-261, 1990.

[13] K. J. Åström and P. Eykhoff, "System identification: a survey," Automatica, vol. 7, pp. 123-162, 1971.

[14] S. A. Billings, "Identification of nonlinear systems-a survey," IEE Proceedings D: Control Theory and Applications, vol. 127, no. 6, pp. 272-285, 1980.

[15] R. Haber and H. Unbehauen, "Structure identification of nonlinear dynamic systems-a survey on input/output approaches," Automatica, vol. 26, no. 4, pp. 651-677, 1990. 

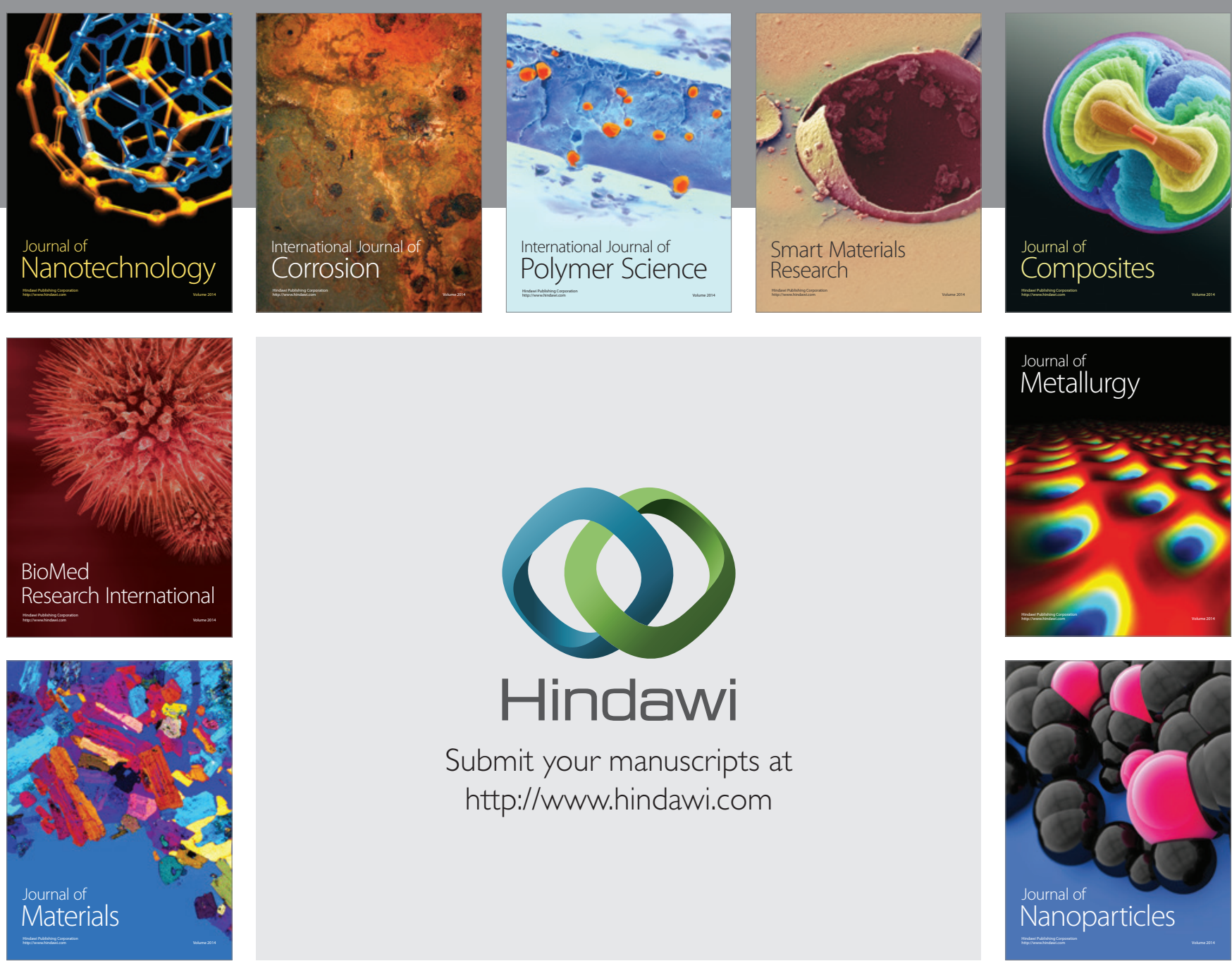

\section{Hindawi}

Submit your manuscripts at

http://www.hindawi.com

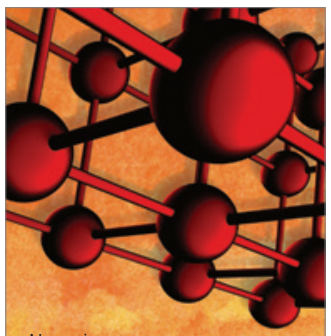

Materials Science and Engineering
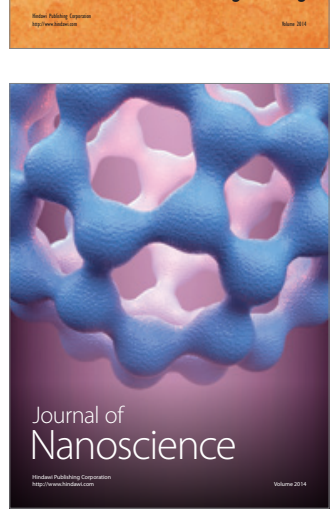
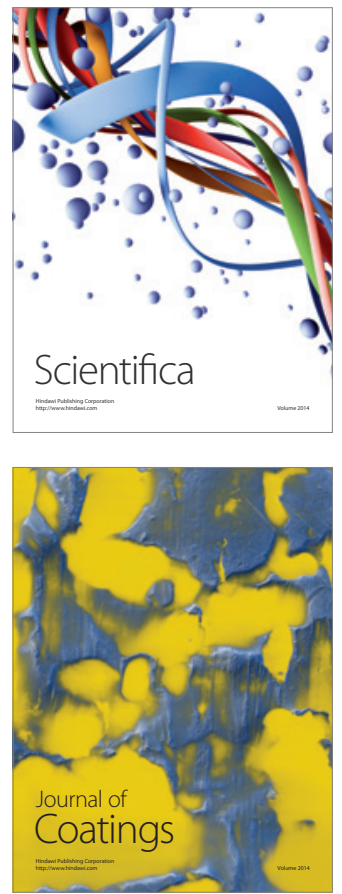
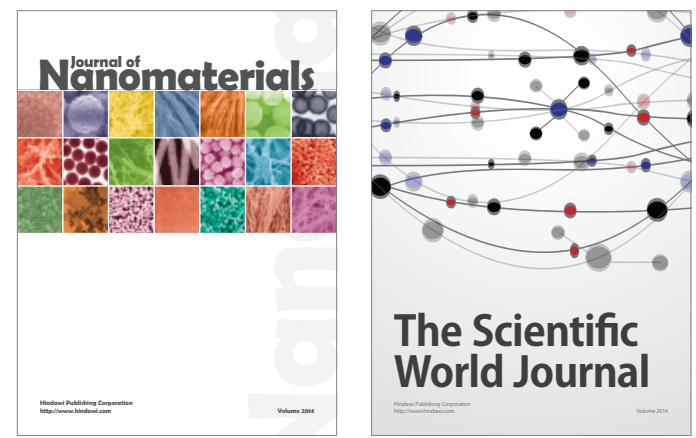

The Scientific World Journal
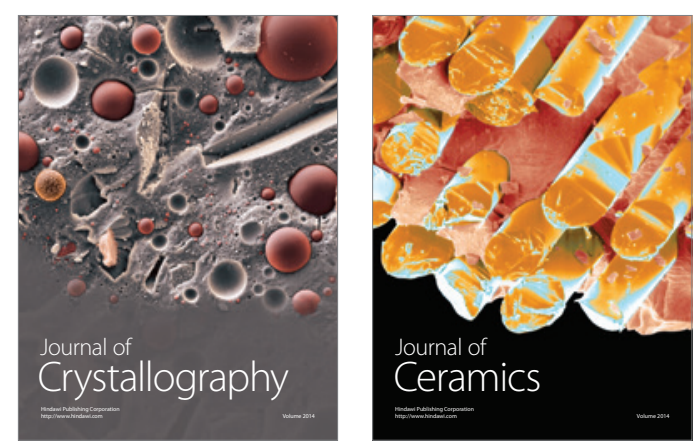
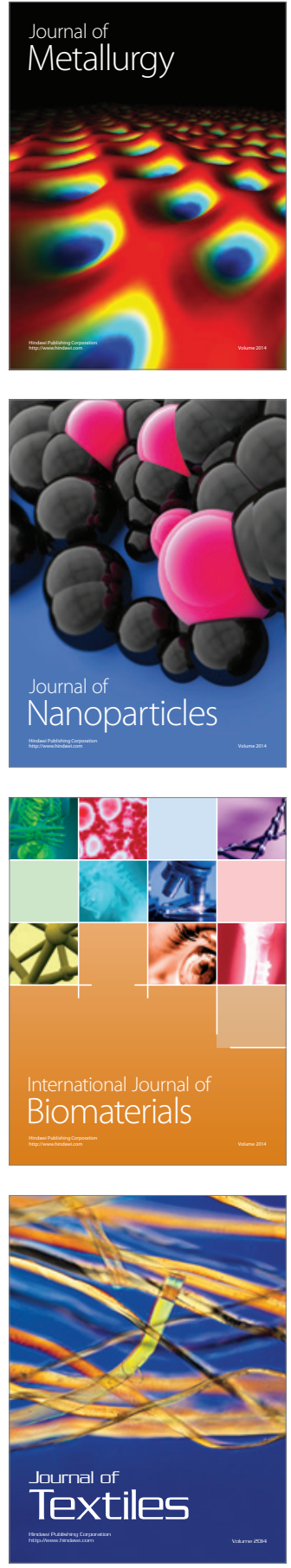